\title{
Withdrawal Scale
}

National Cancer Institute

\section{Source}

National Cancer Institute. Withdrawal Scale. NCI Thesaurus. Code C121294.

A rating scale included in the Behavior Assessment System for Children that measures the tendency of the subject to evade others to avoid social contact. 